\title{
Towards a Personal Knowledge Model (PKM) in Collaborative Environment of School Teachers' Community
}

\author{
Rusli Abdullah ${ }^{1}$ \& Amir Mohamed Talib ${ }^{1}$ \\ ${ }^{1}$ Faculty of Computer Science \& IT, University Putra Malaysia, 43400 UPM, Serdang, Selangor, Malaysia \\ Correspondence: Rusli Abdullah, Faculty of Computer Science \& IT, University Putra Malaysia, 43400 UPM, \\ Serdang, Selangor, Malaysia. E-mail: rusli@fsktm.upm.edu.my
}

Received: July 12, 2012

doi:10.5539/cis.v5n6p50
Accepted: September 28, 2012 Online Published: October 18, 2012

URL: http://dx.doi.org/10.5539/cis.v5n6p50

\begin{abstract}
This paper discusses the concept of teachers' community of practice (CoP) based on personal knowledge management (PKM) in order to facilitate knowledge sharing among them. There are some knowledge are scatted and not well manage around the school teachers. This is lead toward waste of time, cost, and difficulties to find and applying the knowledge when it was needed. In order to solve these problems a PKM model is proposed. The result reveals that in managing the knowledge, the process distribution of its importance in term of knowledge acquisition, storage, dissemination, and their application, encouraging teachers CoP learning, teaching cooperation and knowledge sharing, establishing performance assessment mechanism of knowledge applications and development.
\end{abstract}

Keywords: personal knowledge, personal knowledge management (PKM), knowledge management (KM), school teacher and community of practice $(\mathrm{CoP})$

\section{Introduction}

School teachers' environments offer challenges and opportunities for innovative teaching and enhancement of teacher performance. Critical to this process are strategies to foster transfer of knowledge generation dispositions from teacher to learner.

Personal knowledge includes knowledge gained from formal and informal instruction. Personal knowledge also includes memories, stories we have been told or have told, personal contacts and relationships, books we have read or written, notes, documents, photographs of us or by us, intuitions, what we have learned from our colleagues yesterday, and what we know about everything in our world, from garden plants to nuclear physics. My father learned about farming from his father, from his neighbors, and from extension workers. Some of what he knows could be written down (explicit knowledge) and some cannot (tacit knowledge) (Peterson, 2004).

There are some knowledge such as tacit and explicit are scatted and not in a proper manage around the teachers especially in school system environment. This is lead toward waste of time, cost, and difficulties to find and applying the knowledge when it was needed (Peterson, 2004). Therefore, there is a need for the teacher to organize and produce a mechanism to manage the personal knowledge of teachers as an asset as well as knowledge capital for future purposes especially related to enhance the teacher profession and student achievement, so that It will become more efficiency in school administration as well as to increase good relation with the parents.

Personal knowledge management (PKM) model is a collection of processes that a community of practice (CoP) such as a teachers, students, programmers and developers uses to gather, store, classify, retrieve, search and share knowledge in their daily activities and the way in which these processes support their work activities (Grundspenkis, 2007; Wright, 2005). The increasingly of knowledge workers idea its needed to be responsible for their own growth and learning (Smedley, 2009). It is a top-down approach to knowledge management (KM), as opposed to less traditional, bottom-up KM (Pollard, 2008).

PKM gathers individual skills processes form personal information management (PIM) integration, with KM in addition to input from a variety of disciplines such as management, philosophy and cognitive psychology (Pauleen, 2009). From PKM organizational perspective, the development of the field has been understood in light of expanding knowledge about the permeability of organizational boundaries. From a meta-cognitive 
perspective and human cognitive capabilities, it compares various modalities within human cognition as to their efficacy and competence (Sheridan, 2008). It is an under researched area (Pauleen, 2009).

The requirements of PKM in a knowledge society in which people have access to tremendous amounts of information and communicate with others all over the world are digital, people still predominantly use traditional analogue techniques: Campbell and Maglio (2003) show that simple to-do-lists, paper calendars, address books, and diaries are the most commonly used tools, all of which are analogue paper-based tools. Although email is increasingly used for some personal information tasks that it is mostly unstructured (Whittaker, 2006).

The System or tool features; to acquire - using knowledge map, to store - relate and utilize the knowledge map, to disseminate - agent technology, to apply - utilize and refer to any relevant knowledge. In terms of System Configuration Requirement, the system will be setting up by using Client Server Based System and also by using Groupware Software that is allow the teachers to work together (Apshvalka, 2004). System Operation; Teacher will begin as initiator to deposit knowledge into the system, The knowledge that is deposited will be storing into the system by using knowledge map or knowledge ontology, The student will make used the knowledge of the teachers as they were deposited into system or tool (Scriven, 1994).

In this paper we argue that existing PKM models often focus on supporting knowledge creation and sharing among school teachers' CoP-wide and do not take into account how different initiatives and activities connect at the level of the individual knowledge worker. We introduce PKM as a model that focuses on what is the best related model of managing personal knowledge as an asset such tacit and explicit knowledge of school teacher as a guideline for those who are involving in teaching profession for enhancing the quality of services (QoS) to the stakeholders in a school CoP such as junior teacher and school administrator in term of time, cost and utilization of other resources such as courseware and laboratory in a school management environment.

The reminder of this paper is organized as follows: Section 2 discusses the existing PKM models. Section 3 provides an overview of the research methodology and discusses our proposed PKM model. Section 4 elaborates the findings of the paper. Finally, some concluding remarks presented in Section 5.

\section{Literature Review}

Knowledge is considered inside and outside of the teachers. Knowledge is also consists of tacit and explicit which can be transformed in implicit and explicit respectively. Personal knowledge is relating with anything or teacher matters that can be used as personal purposes or can be shared among CoP, especially the teacher community for their future purposes in term of lesson learn and best practice (Barth, 2003). In this context, sources of knowledge can be divided into two kinds of sources such as internally and externally as shown as Figure 1.

Internal source of knowledge is where the knowledge can come from internally meaning from teacher by himself trough informal of form such as reading, listening and discussion. And externally source knowledge also can become or origin from outsiders of the teacher for their any purposes through formal occasion such training session, seminar and workshop and many others organized by the outsiders (Mulford and Silins, 2009).

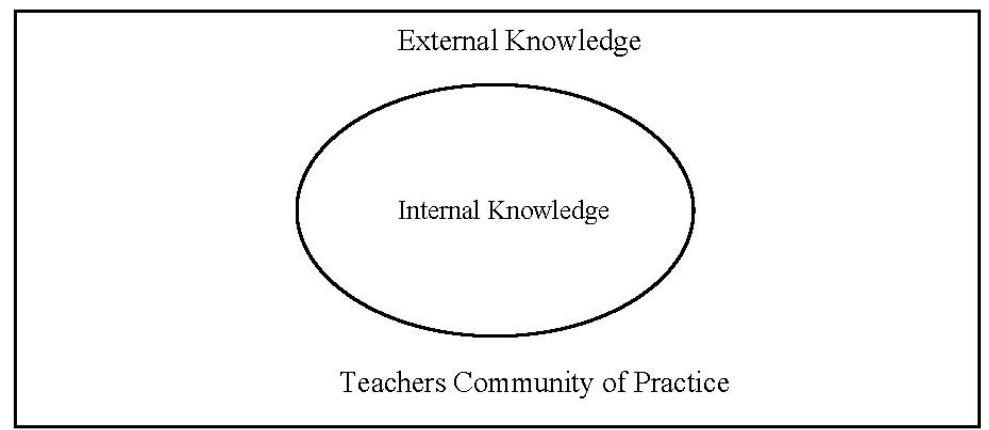

Figure 1. Internal and external knowledge of teachers CoP

The sample of knowledge that involved in a school teacher in a CoP is organized as shown in Figure 2. 


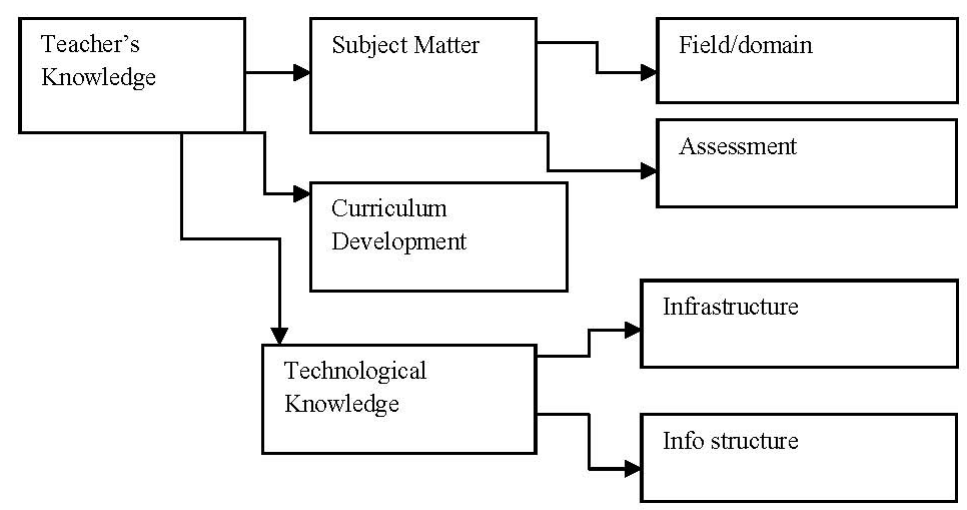

Figure 2. Sample of teacher's knowledge classification

The description of the knowledge can be classified in the following criteria as knowledge metadata in education environment (Barth, 2000). These are including:

a) Subject Matter that is consists of Field of teaching and its assessment;

b) Curriculum Development;

c) Pedagogy;

d) Technological knowledge that is consists of Leaning Management System, and Course Development or Authoring tool;

e) Administrative Knowledge that includes dealing with learning support staff, classroom management and school policy and guidelines for teachers in teaching and learning of the students;

f) Co-Curriculum;

g) Student Affair;

h) Parent Teacher Association.

In the context of knowledge of collaboration especially related to collaborative learning, there are few technologies that could be used for supporting teachers in enhancing their managing of knowledge by using a system called PKM (Barth, 2002). Besides that, they can also leverage the knowledge in increasing the quality of work in a collaborative environment. Furthermore, they can be working together and shared of a variety kind of knowledge internally or externally for any purposes among themselves based on a requirement of CoP.

Facilitating knowledge of school teachers with collaborative environment is not a new area since, (Vygotski, 1978), provides the encouragement contexts in which students play an active role in learning area. Roles of the student and teacher are therefore shifted, as a teachers should collaborate with students in order to help facilitate knowledge construction. Learning area becomes a mutual experience for the teacher and student. (Bruner, 1966) proposed Discovery Learning Theory (DLT) as a constructivism learning theory based in personal learning inquiry. Bruner describes learning as an active process in which learners such as students construct new ideas. Knowledge structures are used to provide an experience organization and intended to allow the learner to go beyond the information given.

To facilitate the knowledge of school teachers' PKM has become one of the issues in the study on contemporary educational reform, and the base of knowledge has become the hot issue of teacher's personal knowledge. Teacher's personal knowledge, derived from the criticism of the traditional teacher's public knowledge, is practical knowledge teachers summarize by experiencing, pondering, perceiving and understanding in their own teaching practice (Argyris \& Schon, 2006).

Teachers' personal knowledge, not having the nature of theoretical knowledge which can conclude the laws of the unknown and make principle expression, is a general knowledge which is formed by virtue of experience to explain, to correct, to deepen the existing knowledge. Meanwhile, being general is not universal. For example, the teachers of the same region who use the same teaching materials and are guided by the same teaching outlines adopt different teaching methods according to the different situations. Besides, teachers from different areas who use different textbooks or have the students of different ages also can share the teaching experience. From this aspect, personal knowledge is general (Mulford \& Kendall, 2007). 
(Avery et al., 2001) have suggested seven key competencies for PKM: access, evaluate, organize, analyze, convey, collaborate, and secure, it seems that analyze, collaborate, and secure are the minor concern of the teachers. Information behavior such as seeking, organizing storing, using, and creating form the basic framework of teacher's PKM. The attributes of PKM include four elements: value, tools, skills, procedures whereas access, evaluation, organization, and creation to denote the four key activities.

PKM can be divided into two main dimensions, personal management and personal knowledge (Zhang, 2009). Zhang has developed a PKM model in relation to organizational knowledge management (OKM) that considers two axes area of management perspectives and knowledge properties, either personal or organizational. These aspects of personal knowledge and organizational knowledge are interconnected through the OPUS Application Program Interface (OAPI) process (personalize, individualize, organizationalize and aggregate), whereby personal knowledge is operationalized and aggregated as organizational knowledge and organizational knowledge is individualized and personalized (Zhang, 2009).

In Nonaka and Takeuchi's Socialization from tacit to tacit knowledge, Externalization from tacit to explicit knowledge, Combination of explicit to explicit knowledge and Internalization from explicit to tacit knowledge (SECI) model is proven that the creation of knowledge is a continuous process of dynamic interactions between tacit and explicit knowledge, with the interaction of the two resulting in new knowledge (Nonaka \& Takeuchi, 1995). Smedley has developed a PKM model based on Nonaka and colleagues' model in which CoP provides support for personal knowledge creation and an expert provides direction (Smedley, 2009). Trust is central to knowledge sharing in SECI model. Nonaka has recently returned back to his SECI model in an attempt to provide a further development to his ideas about knowledge creation (Nonaka \& Von Krogh, 2009).

Jingyuan (2010) proposed a framework of school teachers' PKM to improve teachers' professional development in China. Their proposed framework development analyzed based on the relationship among teacher learning, teacher professional development and school PKM. The result of the framework reveals the knowledge management strategies to improve teacher professional development, including school organizational reforger and knowledge leaders, constructing learning school and organization learning culture, establishing teacher knowledge management system of teacher professional development, encouraging team learning, teaching cooperation and knowledge sharing, establishing performance assessment mechanism of knowledge applications and development.

\section{Methodology}

In order to develop the model of PKM in facilitating of knowledge sharing of school teacher's environment, the methodology shall be carried out in six main steps as shown:

\subsection{Step 1: Literature Review of PKM in a Collaborative Environment of School's Teacher}

This step involves evaluation of existing PKM models, school teaching knowledge literature reviews and how the PKM as system can be used to manage the personal knowledge of the teachers in a CoP in order to achieve their mission statement.

\subsection{Step 2: Conduct a Pre-Survey}

Questionnaire survey shall be used to evaluate the different PKM models used by selected teaching environments such as junior and senior teacher as well as school administrators, so that they can verify the proposed PKM such as system functionality and non-functionality requirement such as maintainability, usability and security that supported from the literature as well as may have additional requirement of any missing variability or functions of PKM as a system in providing the knowledge of school teachers in a CoP. The pre-survey shall cover school's teacher collaborative activities and PKM improvement required. Also, usage of collaborative tools and PKM improvement sharing tools shall be identified.

\subsection{Step 3: Formulation of the Proposed Model}

In this step the formulation of our proposed PKM model of developing a PKM model facilitating of knowledge sharing in a collaborative environment of school's teacher is discussed as follow:

Based on earlier literature reviews and pre-survey results, areas of concerns and different PKM improvement requirement areas are noted. Build a PKM model based on the knowledge creation and sharing techniques, KM tools and teaching environment activities. The PKM as a tool for the teacher's community is proposed based on the following criteria, and also shown in Figure 3. To formulate our model a numbers of tasks have been is discussed as follow: 


\subsubsection{System Objectives}

To organize and produce a mechanism to manage the personal knowledge of teachers as an asset as well as knowledge capital for future purposes especially related to enhance the student achievement, and to become high performing in education in term of efficiency in school administration as well as to increase good relation with the parents.

\subsubsection{System or Tool Features}

To acquire - using knowledge map; To store - relate and utilize the knowledge map; To disseminate - agent technology; To apply - utilize and refer to any relevant knowledge.

\subsubsection{System Configuration Requirement}

Client Server Based System; Probably is Groupware Software that is come together with database management system.

\subsubsection{System Operation}

Teacher will begin as initiator to deposit knowledge into the system; The knowledge that is deposited will be storing into the system by using knowledge map or knowledge ontology; The student will make used the knowledge of the teachers as they were deposited into system or tool.

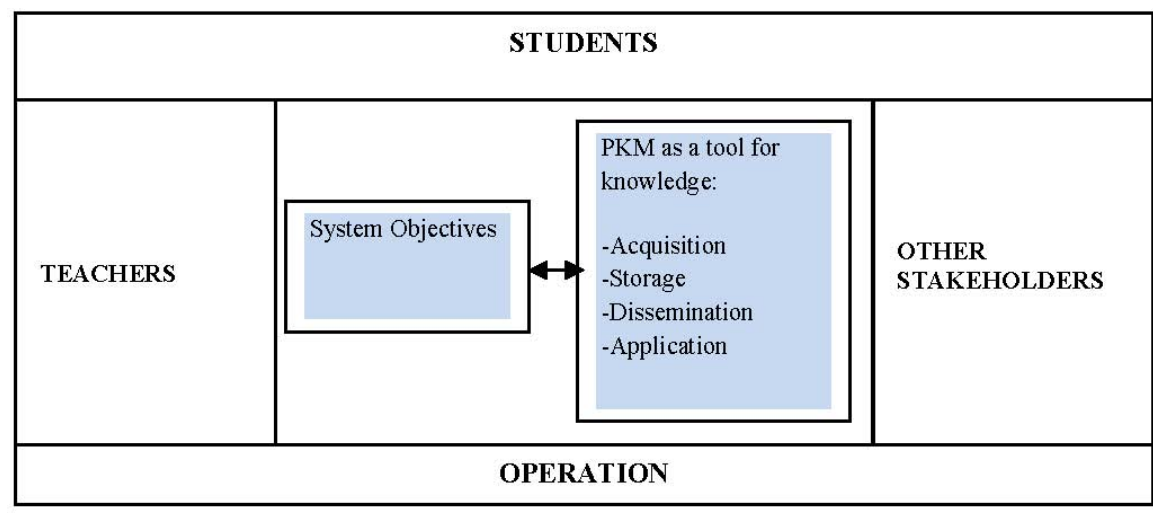

Figure 3. The relationship of the system criteria for PKM proposed model

\subsection{Step 4: System Design}

System design is illustrating the process to architectural design of the model into its component-based system with regards on PKM together in school teachers' community.

\subsection{Step 5: System Evaluation}

Another round of questionnaire called post-survey in order not only to verify and validate the model but also a part to enhancing of a comprehensive system model specification is discussed.

\subsection{Step 6: Conclusion}

The summarization of finding of both pre-survey and post-survey that has been done on in producing the KMS model for managing knowledge of school teacher in their domain of education environment are concluded.

\section{Results and Discussion}

The PKM model development in the context of school teachers' CoP has been gone rapidly. Based on this, there is a significant resulting shown that the PKM should accommodate the following features or components, in order to become relevant to serve the teachers.

A survey was conducted in selected twenty seven respondents from Faculty of Computer Science and Information Technology (FSKTM), Universiti Putra Malaysia (UPM), participated in this research. Thirty three questionnaires were distributed to the respondents, and twenty seven questionnaires were returned. The result of the survey contributed to the formulation of the PKM model development. PKM model was in two aspects: quantitatively and qualitatively via a survey questionnaire.

The quantitative evaluation is limited to descriptive statistics on KM concept and understanding, internal and external knowledge gathering, school teachers' $\mathrm{CoP}$ and knowledge sharing techniques. A more concrete 
qualitative evaluation is needed to properly evaluate whether PKM model has achieved its goal.

\subsection{The Process of PKM in School Teachers' CoP}

As a part of PKM as a system which is implemented in teachers' CoP, they are agreed that in managing the knowledge, the process distribution of its importance in term of knowledge acquisition, storage, dissemination, and their application as illustrated in Figure 4.

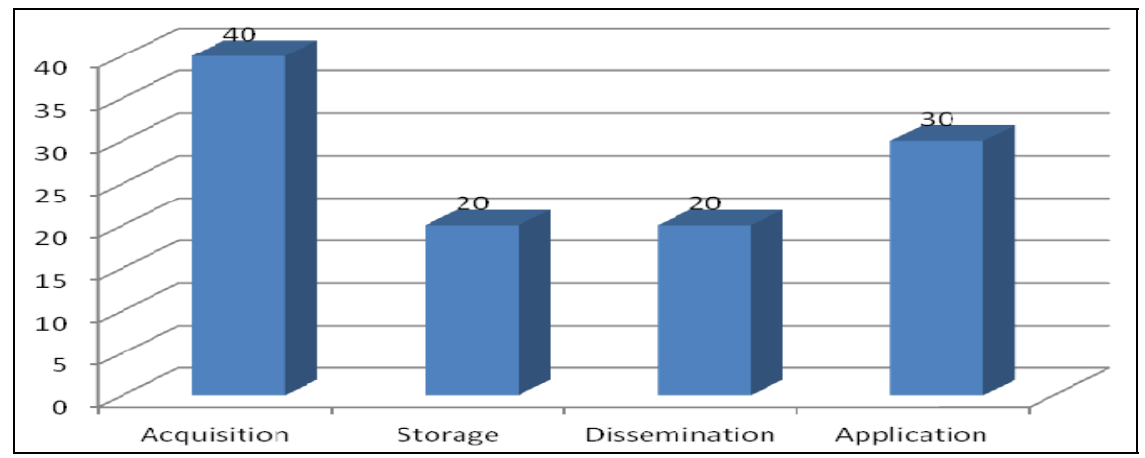

Figure 4. Paragraph of the percentage of PKM

\subsection{Suggested Knowledge's Strategies of PKM}

Besides that, the percentage of technologies requirement in supporting knowledge of teachers' community based on Knowledge application, Knowledge dissemination, Knowledge storage and Knowledge acquisition as illustrated in Figure 5.

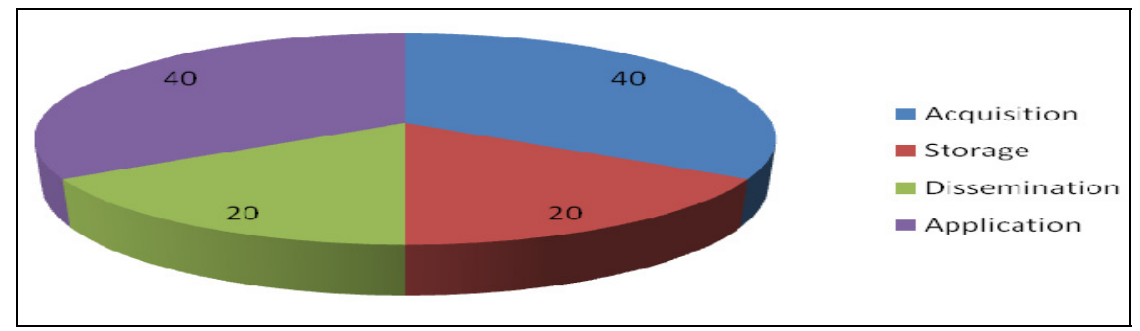

Figure 5. Pie chart of technologies requirement in teacher CoP

\subsection{Non-functionality Requirements of PKM}

Meanwhile, the percentage of non-functionality requirement is also importance in developing PKM for serving the school teachers CoP in managing their knowledge of education domain environment as illustrated in Figure 6. These are including attributes such as usability; learn ability, ease of use, user friendly, maintainability, performance, and security.

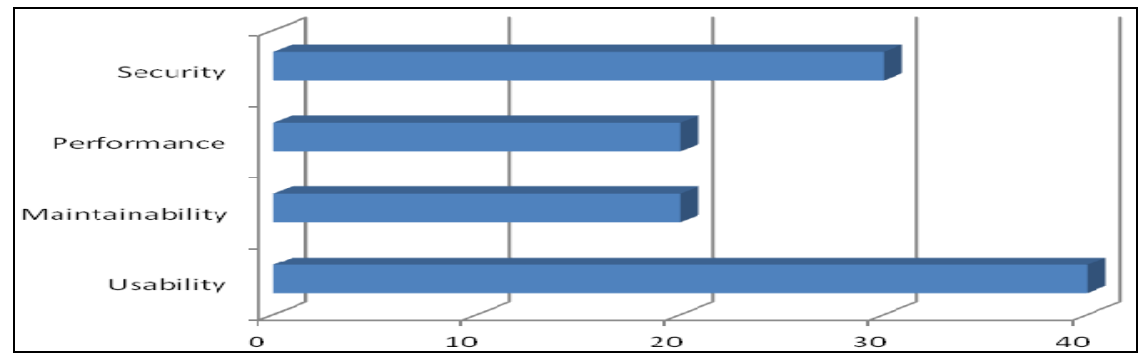

Figure 6. Bar chart of non-functionality requirement of PKM in teacher CoP 


\section{Conclusions and Future Work}

This paper examines the possibility of enhancing the performance of school teachers services strategies based on PKM techniques. The central research questions are to ascertain on what is the best related model of managing personal knowledge as an asset of school teacher as a guideline for those who are involving in teaching profession to the student stakeholders in school $\mathrm{CoP}$ in term of time, cost and utilization of resources in school management environment as well as how to enhance the teacher profession and indirectly to deliver good services to the students. A model was identified for a conceptual framework of this study. During the survey this model was validated as a sufficient framework to explain the PKM of teachers' community. The results reveals technology requirement in supporting knowledge of teachers' community based on Knowledge application, Knowledge dissemination, Knowledge storage and Knowledge acquisition.

For future work, it is good to be considered on how school teachers knowledge's can be shared and used by teachers' CoP that may be using any devices especially through mobile computing development since this project is only considered for accessing in a PKM as common devices (client server based environment through desktop technology) only.

\section{References}

Apshvalka, D. (2004). Personal Knowledge Management. pp. 17-22.

Argyris, C., \& Schon, D. (2006). Theory in Practice: Increasing Professional Effectiveness (pp. 230-232). Higher Education Scries.

Averey, S., Brooks, R., Dorsey, P., \& O’Conner, P. (2001). Personal Knowledge Management: Framework for Integration and Partnerships. PKM Presentation at ASCUE 2001, Myrtle Beach.

Barth, S. (2000). The Power of One (pp. 30-36). Knowledge Management Magazine.

Barth, S. (2002). The PKM Manifesto. The PKM Manifesto, Series of PKM Manifesto.

Barth, S. (2003). A framework for Personal Knowledge Management Tools. Km World, 12(1), 20-21.

Bruner, J. S. (1966). Toward A theory of Instruction, Taylor \& Francis. http://dx.doi.org/10.1119/1.2350966

Campbell, C., \& Maglio, P. (2003). Supporting notable information in office work. In CHI, pp. 902-903.

Grundspenkis, J. (2007). Agent Based Approach for Organization and Personal Knowledge Modelling: Knowledge Management Perspective. Journal of Intelligent Manufacturing, 18(4), 451-457. http://dx.doi.org/10.1007/s10845-007-0052-6

Mulford, B., \& Kendall, D. (2007). Successful School Leadership: What is it and Who Decides? Australian Journal of Education-Hawthorn, 51(3), 228.

Mulford, B., \& Silins, H. (2009). Revised Models and Conceptualization of Successful School Principal-ship in Tasmania. Successful School Principalship in Tasmania. Launceston, Tasmania: Faculty of Education, University of Tasmania.

Nonaka, I., \& Takeuchi, H. (1995). The Knowledge Creating Company: How Japanese Companies Create the Dynamics of Innovation (p. 284). New York: Oxford University Press.

Nonaka, I., \& von Krogh, G. (2009). Tacit Knowledge and Knowledge Conversion: Controversy and Advancement in Organizational Knowledge Creation Theory. Organization Science, 20(3), 635-652. http://dx.doi.org/10.1287/orsc.1080.0412

Pauleen, D. (2009). Personal Knowledge Management: Putting the 'Person' back into the Knowledge Equation. Online Information Review, 33(2), 221-224. http://dx.doi.org/10.1108/14684520910951177

Peterson, K. (2004). Research on School Teacher Evaluation. NASSP Bulletin, 88(639), 60-79. http://dx.doi.org/10.1177/019263650408863906

Scriven, M. (1994). Duties of the Teacher. Journal of Personnel Evaluation in Education, 8(2), 151-184. http://dx.doi.org/10.1007/BF00972261

Sheridan, W. (2008). How to Think Like a knowledge Worker, United Nations Public Administration Network.

Smedley, J. (2009). Modelling Personal Knowledge Management. OR Insight, 22(4), 221-233. http://dx.doi.org/10.1057/ori.2009.11

Vygotski, L. S. (1978). Mind in Society: The Development of Higher Psychological Processes. Harvard Univ Pr.

Whittaker, S., Bellotti, V., \& Gwizdka, J. (2006). Email in personal information management. Commun. ACM, 
49(1), 68-73. http://dx.doi.org/10.1145/1107458.1107494

Wright, K. (2005). Personal Knowledge Management: Supporting Individual Knowledge Worker Performance. Knowledge Management Research and Practice, 3(3), 156-165. http://dx.doi.org/10.1057/palgrave.kmrp.8500061

Zhang, Z. (2009). Personalising Organisational Knowledge and Organisationalising Personal Knowledge. Online Information Review, 33(2), 237-256. http://dx.doi.org/10.1108/14684520910951195

Zhao, J. (2010). School Knowledge Management Framework and Strategies: The New Perspective on Teacher Professional Development. Computers in Human Behavior, 26(2), 168-175. http://dx.doi.org/10.1016/j.chb.2009.10.009 